\title{
Food intake in a West African village. Estimation of food intake from a shared bowl
}

\author{
BY GEOFFREY J. HUDSON \\ MRC Dunn Clinical Nutrition Centre, Hills Road, Cambridge CB2 $2 D H$ and \\ MRC Compound, Keneba, West Kiang, The Gambia, West Africa
}

(Received 4 January 1994 - Revised 5 July 1994 - Accepted 24 August 1994)

\begin{abstract}
Novel methodology is described for the estimation of food intake in the particularly difficult circumstance where groups of people eat directly from a shared bowl of cooked food. Detailed observation and measurement of meal preparation is combined with food table values for composition to calculate the nutrient content of each meal. The distribution of food between individuals is estimated by a suitable algorithm. The ability of the algorithm to identify seasonal changes in energy intakes is demonstrated by comparison of the calculated energy intakes with values for the total energy expenditure of free-living adult male subjects, as measured by the stable isotope, doubly-labelled water technique. This comparison suggests that the energy intake calculated from detailed observation of two cooked meals per day is equivalent to approximately $80 \%$ of the total energy expenditure and, by inference, total dietary energy intake. The remaining energy intake may well be derived from uncooked 'snack foods', such as raw fruit and vegetables, or from cooked food obtained, by purchase or as a gift, away from the home. This is the first description of a successful method for the estimation of food intake when people eat directly from shared bowls of food.
\end{abstract}

West Africa: Food intake: Shared bowls: Energy intake: Energy expenditure

Accurate measurement of the food intake of free-living humans is notoriously difficult (Bingham, 1987, 1991; Borelli, 1990). When a group of people eat directly from a shared bowl of food, measurement of the food intake of any individual within that group is impossible. The present paper describes the successful application of novel methodology for the estimation of food intake under these particular circumstances. Validation of the data is one of the problems to be solved in any measurement of food intake. In the work described here the stable isotope, doubly-labelled water technique is used to measure the total energy expenditure of free-living subjects. The values obtained for energy expenditure are used as reference values for comparison with the values for dietary energy intakes, which are derived from detailed studies of food preparation and cooking. Weights of cooked food are used with food table values for composition to calculate the energy content of the food, and various algorithms are examined for calculation of the distribution of food between the individuals who shared it.

SUBJECTS, MATERIALS AND METHODS

Ethical permission for this work was granted by the joint MRC/Gambian Government Scientific Co-ordinating Committee and Ethical Committee.

The studies took place in the West Kiang District of The Gambia, West Africa. The fieldwork was done by a team of MRC Gambian fieldworkers led by Mr Baba S. N. Jobarteh. 
The fieldworkers, who were skilled in dietary surveys, all spoke English and Mandinka (the local language) as well as their own tribal language (mainly Jola).

\section{Study design and subjects}

The study was divided into three phases. Phase 1 was a field trial of the methodology, designed to identify potential problems, to act as a survey of co-operation, and to determine whether there was any marked difference in food type or preparation within or between villages. This was done as a population study in 1987. At that time there were 208 sinkiros in Keneba. (A sinkiro is a cooking unit within the family structure. Each sinkiro has its appointed cook(s) and cooking hut, and will provide food for certain members of the family on a regular basis. When there is more than one sinkiro within a family the male head of the household may receive food from each.) Every sinkiro in Keneba was visited at least once, and so were some in the nearby villages of Kanton Kunda and Manduar. There was no obvious difference in type of food or methods of preparation between the villages, and it was decided to limit the next part of the study to Keneba.

Phase 2 took place in 1988 and was confined to twenty families who were identified by the fieldworkers as likely to remain in a more intensive study.

Phase 3 took place in 1989 and was focused throughout on ten families selected for their demonstrated co-operation in earlier studies and their stated willingness to continue. Food intake was measured for all the families. Seven adult males took part in studies of total energy expenditure using the doubly-labelled water method (Coward, 1988; Coward \& Cole, 1991); the men received doses of doubly-labelled water on four separate occasions, approximately 3 months apart. Other adult male volunteers provided samples of urine as a control for fluctuations in background levels of enrichment of the stable isotopes ${ }^{18} \mathrm{O}$ and ${ }^{2} \mathrm{H}$. Anthropometric data were collected on four separate occasions for all family members over the age of 12 years (Hudson, 1992).

\section{Estimation of the distribution between individuals of food from a shared bowl}

The method of estimating food intake described here requires detailed knowledge of the composition of each cooked meal. A separate two-letter code was used for the identification of the ingredients of each meal, which allows cross-reference to the compositional data used for the calculation of the energy content of each meal. Some examples of the energy values used, and their origins, are given in Table 1.

Once a value is obtained for the energy content of a bowl of food that is going to be shared by a group of people, the problem to be solved is how to estimate the amount of food that each person is likely to eat.

\section{Observation protocol}

'Breakfast' is rarely cooked in Keneba; instead, two meals, referred to here as lunch and dinner, are usually cooked each day. Lunch is a meal eaten at about midday and dinner is the meal eaten in the evening, often quite late at night when small children are asleep; a bowl of food called a seeta is often set aside for children to eat the next day. During the farming season, lunch may be cooked early in the morning and taken to the fields to be eaten later, or a cook may remain in the compound and children will take the food along later. Fieldworkers observed and recorded on pre-printed forms the details of the preparation of the two meals cooked by each sinkiro on each study day. Every ingredient was identified and was weighed just before it was put into the cooking pot. Most meals consisted of rice and a sauce, cooked separately and sequentially on a log fire. Batterypowered electronic scales were used for weighing people (to the nearest $100 \mathrm{~g}$ ) and for weighing food (to the nearest $0 \cdot 1 \mathrm{~g}$ ). The observer (or a relief) stayed in the compound while 
Table 1. Energy values and water contents for ingredients used in the calculation of food intake by subjects in a West African village

\begin{tabular}{|c|c|c|c|c|}
\hline \multirow[b]{2}{*}{ Food } & \multirow{2}{*}{$\begin{array}{c}\text { Water } \\
\text { content } \\
(\mathrm{g} / \mathrm{kg})\end{array}$} & \multicolumn{2}{|c|}{ Energy content } & \multirow[b]{2}{*}{ Reference } \\
\hline & & $(\mathrm{kJ} / \mathrm{kg})$ & $(\mathrm{kcal} / 100 \mathrm{~g})$ & \\
\hline Aubergine (Solanum melongena) & 930 & 586 & 14 & Paul \& Southgate (1978) \\
\hline Baobab leaf (Adansonia digitata) & 910 & 1171 & 28 & Platt (1962) \\
\hline Baobab milk & 880 & 1925 & 46 & In-house values* \\
\hline Bitter tomato (Solanum incanum) & 930 & 586 & 14 & In-house values* \\
\hline Bush cassava (Dioscorea prahensalis/bulbifera) & 600 & 6402 & 153 & Platt (1962) \\
\hline Bush mango (Cordyla africana) & 830 & 2469 & 59 & Platt (1962) \\
\hline Cabbage (Brassica oleracea) & 930 & 962 & 23 & Platt (1962) \\
\hline Cassava (Manihot esculenta) & 600 & 6402 & 153 & Platt (1962) \\
\hline Chicken & 650 & 9623 & 230 & Paul \& Southgate (1978) \\
\hline Chilli (Capsicum frutescens), fresh & 940 & 628 & 15 & Paul \& Southgate (1978) \\
\hline Chilli, dry & 80 & 12175 & 291 & Platt (1962) \\
\hline Findo flour (Digitaria exilis) & 60 & 14518 & 347 & Platt (1962) \\
\hline Findo millet & 60 & 15480 & 370 & Platt (1962) \\
\hline Fish, dry & 200 & 12929 & 309 & Platt (1962) \\
\hline Green beans (Vigna unguiculata) & 700 & 4351 & 104 & In-house values* \\
\hline Groundnut leaf (Arachis hypogaea) & 910 & 1171 & 28 & Platt (1962) \\
\hline Groundnut oil & 0 & 37656 & 900 & Paul \& Southgate (1978) \\
\hline Groundnut, raw & 45 & 23849 & 570 & Paul \& Southgate (1978) \\
\hline Groundnut, roast & 45 & 23849 & 570 & Paul \& Southgate (1978) \\
\hline Guava (Psidium guajava) & 830 & 2594 & 62 & Paul \& Southgate (1978) \\
\hline Honey & 230 & 11966 & 286 & Paul \& Southgate (1978) \\
\hline Jambanduro leaf (Cassia tora) & 910 & 1171 & 28 & Platt (1962) \\
\hline Kucha leaf (Hibiscus sabdariffa) & 910 & 1171 & 28 & Platt (1962) \\
\hline Lime (Citrus aurantifolia) & 900 & 1506 & 36 & Platt (1962) \\
\hline Locust bean (Parkia biglobosa) & 100 & 15899 & 380 & Platt (1962) \\
\hline Maize (Zea mays) & 120 & 15188 & 363 & Platt (1962) \\
\hline Maize flour & 120 & 15146 & 362 & Platt (1962) \\
\hline Mango (Mangifera indica) & 830 & 2469 & 59 & Platt (1962) \\
\hline Milk, fresh & 880 & 2720 & 65 & Paul \& Southgate (1978) \\
\hline Milk, powdered & 30 & 20501 & 490 & Paul \& Southgate (1978) \\
\hline Milk, sour & 880 & 2270 & 65 & Paul \& Southgate (1978) \\
\hline Milk, tinned & 686 & 6611 & 158 & Paul \& Southgate (1978) \\
\hline Millet (any) & 110 & 14853 & 355 & Platt (1962) \\
\hline Morongo leaf (Amaranthus caudatus/viridis) & 910 & 1172 & 28 & Platt (1962) \\
\hline Nebedayo leaf (Moringo oleifera) & 910 & 1172 & 28 & Platt (1962) \\
\hline Oil (any) & 0 & 37656 & 900 & Paul \& Southgate (1978) \\
\hline Okra (Hibiscus esculentus) & 900 & 711 & 17 & Paul \& Southgate (1978) \\
\hline Okra leaf & 910 & 1172 & 28 & Platt (1962) \\
\hline Onion (Allium cepa) & 930 & 962 & 23 & Paul \& Southgate (1978) \\
\hline Onion leaf & 910 & 1172 & 28 & Platt (1962) \\
\hline Orange (Citrus sinensis) & 860 & 1464 & 35 & Paul \& Southgate (1978) \\
\hline Palm fruit kernel (Elaeis guineensis) & 40 & 12845 & 307 & In-house values* \\
\hline Palm oil & 0 & 37656 & 900 & Paul \& Southgate (1978) \\
\hline Pawpaw (Carica papaya) & 890 & 1632 & 39 & Platt (1962) \\
\hline Pumpkin (Cucurbita maxima) & 950 & 628 & 15 & Paul \& Southgate (1978) \\
\hline Rice (Oryza sativa) & 120 & 15104 & 361 & Platt (1962) \\
\hline Rice flour & 120 & 15313 & 366 & Paul \& Southgate (1978) \\
\hline Roast rice & 120 & 15104 & 361 & Paul \& Southgate (1978) \\
\hline Sanyo flour (Pennisetum typhoideum) & 100 & 15272 & 365 & Platt (1962) \\
\hline Sanyo millet & 100 & 15272 & 365 & Platt (1962) \\
\hline Shellfish & 830 & 2929 & 70 & Platt (1962) \\
\hline Sora leaf (Leptadenia lancifolia/hastata) & 910 & 1172 & 28 & Platt (1962) \\
\hline Sorghum (Sorghum gambicum/margaritiferum) & 120 & 14770 & 353 & Platt (1962) \\
\hline Spring onion (Allium cepa) & 870 & 1464 & 35 & Paul \& Southgate (1978) \\
\hline
\end{tabular}


Table 1. (cont.)

\begin{tabular}{lcccc}
\hline \hline & $\begin{array}{c}\text { Water } \\
\text { content } \\
\text { Food }\end{array}$ & \multicolumn{2}{c}{ Energy content } & \\
& $(\mathrm{g} / \mathrm{kg})$ & $(\mathrm{kJ} / \mathrm{kg})$ & $(\mathrm{kcal} / 100 \mathrm{~g})$ & Reference \\
\hline Sugar & 0 & 16485 & 394 & Paul \& Southgate (1978) \\
Suno flour (Pennisetum gambiense) & 100 & 15272 & 365 & Platt (1962) \\
Suno millet & 110 & 14853 & 355 & Platt (1962) \\
Surro leaf (Ficus gnecephalocarpa) & 910 & 1172 & 28 & Platt (1962) \\
Sweet pepper (Capsicum annuum var. grossum) & 935 & 628 & 15 & Paul \& Southgate (1978) \\
Sweet potato leaf (Ipomaea batatas) & 850 & 2008 & 48 & Platt (1962) \\
Sweet potato & 700 & 3807 & 91 & Paul \& Southgate (1978) \\
Tomato (Lycopersicon esculentum) & 930 & 586 & 14 & Paul \& Southgate (1978) \\
Tomato paste & 657 & 2803 & 67 & Paul \& Southgate (1978) \\
Wheat flour (Aestivum triticale) & 140 & 13682 & 327 & Paul \& Southgate (1978) \\
\hline \hline
\end{tabular}

* Calculated as for Paul \& Southgate (1978).

the meal was being cooked, ensuring that no last-minute addition went undetected. When the meal was ready, the weight of each eating bowl was determined when empty, after the addition of the staple, again after the addition of water or sauce, and so on, and each bowl was assigned a number. The age, sex and body weight of each person, and the number of the bowl from which they were going to eat was recorded. The whole procedure took place in the compound where the meal preparation was observed. The time required of each subject was thus short and the procedure seemed to be well tolerated. The observer waited in the compound until people had finished eating inside their houses, and then weighed any food that remained uneaten.

\section{Energy values}

The database contains a reference table of the energy content of individual ingredients as far as is possible (see Table 1). Some of the items encountered in this study have not been analysed, and various devices have been adopted. For example, a single value has been used for fresh fish, irrespective of species. The species eaten were all non-fatty fish and differences in energy content are likely to be small. Any flour made from two cereals was assumed to be an equal mixture. The use of these values was infrequent and is unlikely to have had any significant effect on the results.

\section{Calculation of the energy content of each eating bowl of food}

Two assumptions are implicit in the calculation of the energy content of each eating bowl of cooked food: (1) all food is removed from the cooking pot; and (2) each element of the meal (e.g. staple, sauce) is homogeneous. Although neither is true, the errors are unlikely to be large and these assumptions greatly simplify the calculations.

The weight of each raw ingredient of the staple element of the meal was recorded. Average compositional data were used to calculate the energy content of each ingredient and hence the total energy content of the staple element of the meal. The weights of the empty eating bowls and the weights of these bowls after the staple has been added allow calculation of the total weight of cooked staple and the proportion of the total cooked staple that is in each bowl. Application of these proportions to the total energy content yields the amount of energy contributed by the staple element to each bowl of food. Similar calculations were used for the sauce and fish/meat elements of the meal. 
Various analytical schemes were examined for estimating the distribution of the food, and hence the dietary energy, between the people who ate the food (Hudson, 1992). The chosen scheme was devised to assume a distribution of food that recognized a nonproportional relationship between energy requirements and body weights (Anderson $e t$ al. 1977). Mathematical factors were calculated for each sex $(X)$ /age $(Y)$ classification using the algorithm:

$$
\left.X / Y \text { factor }={ }^{\operatorname{lnt}}[(W t-10 \cdot 5) / 10)\right] \times 0 \cdot 25+1 \cdot 5,
$$

where ${ }^{\text {int }}[x]$ is the integer of $x$ and $W t$ is body weight (in $\mathrm{kg}$ ) for individuals who weigh more than $10.5 \mathrm{~kg}$; subjects who weigh less than $10.5 \mathrm{~kg}$ are assigned a factor of 1.0 . Any algorithm that is chosen is, of course, arbitrary and some form of reference is needed to decide whether the results obtained by its application are reasonable.

\section{Doses}

For each measurement period a single batch of doubly-labelled water was prepared and divided to give the seven doses required. Water enriched for ${ }^{18} \mathrm{O}$ (Isotec Inc., Miamisburg, OH, USA) was mixed with ${ }^{2} \mathrm{H}_{2} \mathrm{O}$ (Sigma, Poole, Dorset; $99 \cdot 8 \%$ pure), after each had been passed through a Sartorius Minisart $0.45 \mu \mathrm{m}$ filter, to give an ${ }^{18} \mathrm{O}:{ }^{2} \mathrm{H}$ ratio of $2 \cdot 4: 1$. The mixture was divided into screw-top glass bottles and then autoclaved at $103.5 \mathrm{kPa}$ for $50 \mathrm{~min}$. A sample of the mixture was retained in Cambridge for later analysis. The dose volume was chosen to provide $0.07 \mathrm{~g}{ }^{2} \mathrm{H}$ and $0.17 \mathrm{~g}{ }^{18} \mathrm{O} / \mathrm{kg}$ body weight, assuming an average body weight of $60 \mathrm{~kg}$.

\section{Dose administration}

Subjects came to the Keneba laboratory and a fieldworker explained carefully what was required. A capped bottle of doubly-labelled water and a plastic drinking straw were weighed to the nearest $100 \mathrm{mg}$. The bottle was opened and the straw was inserted. The subject drank the labelled water rapidly, followed by approximately $200 \mathrm{ml}$ tap water to ensure that all the dose was swallowed; this procedure took only a few seconds. Immediately, the straw was pushed into the bottle, which was capped and weighed again to ascertain the amount of labelled water ingested by the subject.

\section{Sample collection}

Each subject provided a specimen of his second micturition of the day before receiving the dose of doubly-labelled water. This pre-dose sample served as a measure of the background levels of enrichment of the two isotopes for each subject. The subjects returned to provide a further sample of urine between 4 and $6 \mathrm{~h}$ after receiving the labelled water. Not all subjects returned to the laboratory on every occasion, and this has been taken into account in the subsequent analysis of the data. The subjects were asked to come to the laboratory to provide a sample of their second micturition on each of the next 10 consecutive days. Again, they did not always do this. Every attempt was made to track down 'missing' subjects but occasionally they had gone away for a few days. Nonetheless, the collections were mostly complete. All samples of urine were obtained by direct passage into a prelabelled, Sterilin plastic screw-top $25 \mathrm{ml}$ container. Upon receipt of samples in the laboratory, three subsamples of approximately $3.5 \mathrm{ml}$ each were taken by pipette into plastic screw-top $5 \mathrm{ml}$ containers. The containers were labelled and stored at $-20^{\circ}$, as were the original containers. Two subsamples of each sample were air-freighted to Cambridge for analysis. Unfortunately, some of the subsamples from the April measurements were lost somewhere between Keneba and Cambridge, which influenced the method of analysis chosen for these subsamples. 


\section{Measurement of isotope enrichment}

The levels of enrichment of the two isotopes in the samples were measured by isotope-ratio mass spectrometry. Different mass spectrometers give different absolute values for the isotopic enrichment of a particular sample. Therefore, observed values are related to international standards. All the enrichment values in this work were in units of $\delta \%$ relative to standard mean ocean water (International Dietary Energy Consultancy Group, 1990). Every analytical batch of samples included a sample of the appropriate diluted dose.

${ }^{18} \mathrm{O}$ was measured with a VG Sira 10 instrument (VG Instruments, Middlewich, Cheshire) for the samples collected in January, July and October, and these values have been used in the analysis of data. ${ }^{2} \mathrm{H}$ and ${ }^{18} \mathrm{O}$ were measured with the VG Aqua Sira instrument for all samples. All these ${ }^{2} \mathrm{H}$ values and the ${ }^{18} \mathrm{O}$ values for the April samples were used in the analysis of data.

\section{RESULTS}

The diet

The success of any study of food intake depends on accurate knowledge of the diet, and of the habits and customs associated with the cooking, distribution and eating of food. The approach used in the present work was to record detailed qualitative and quantitative data for the ingredients used in each cooked meal. Average food table values for the energy content of each ingredient (Table 1) were used to calculate the energy content of each meal. At first sight, the diet in Keneba is fairly monotonous, but the variety in the diet is provided by the sauces. Tia durango, a sauce made with roasted groundnuts, is the preferred sauce and is usually replaced by leaf sauces only when stocks of groundnuts are exhausted, so that there are seasonal changes in the nature of the diet (Hudson \& Day, 1989). In the present study, every ingredient was identified, weighed and recorded during the preparation of each meal studied. The same information can be used for the calculation of any nutrient of interest if compositional data are available for the ingredients, and such values exist for many of the individual components of the diet described here, none of which is unique to Keneba (Platt, 1962; Paul \& Southgate, 1978).

Most families cooked only two meals per day, with surplus from the evening meal being eaten the following morning. Richer families may have food items such as locally baked bread and milk, often soured, for breakfast. Each cooked meal usually consists of a cereal staple and a sauce. Fish or, more rarely, meat may be included in the meal.

No attempt was made to measure snack foods, and so no data for foods like raw fruit, raw carrots, raw groundnuts, dempetengo (parched rice cooked in the fields during the rice harvest) or roast maize cobs were obtained. These types of food are available only seasonally. The diet in Keneba has changed considerably over a decade and continues to do so. The most striking change is in the percentage frequency consumption of rice (Table 2), which represented less than $50 \%$ of all cereals in 1981 but more than $90 \%$ in 1987 and 1988. This is a reflection of the year-round availability of aid rice and the villagers' ability to buy it. Findo, a cultivated grass known as 'hungry millet', has disappeared from the diet.

\section{Staples}

Table 3 shows the average weights of raw staple used per meal in 1987, 1988 and 1989. Crude estimates of the amounts of staple used by a family in a year can be made from these figures. For example: rice represents $85.44 \%$ of the staples by frequency; $85.44 \%$ of a year is approximately $312 \mathrm{~d}$; the grand mean amount of rice per meal is $1.337 \mathrm{~kg}$; so, the 'average family', consuming two meals per day, eats approximately $834 \mathrm{~kg}$ rice/year. 
Table 2. Percentage frequency of occurrence of six staples in the diet of West African villagers*

\begin{tabular}{|c|c|c|c|c|}
\hline Staple & 1981 & 1987 & 1988 & 1989 \\
\hline Rice (Oryza sativa) & $47 \cdot 2$ & 91.0 & $90 \cdot 6$ & $78 \cdot 7$ \\
\hline Sorghum (Sorghum gambicum/margaritiferum) & $14 \cdot 0$ & $4 \cdot 5$ & 0.9 & $1 \cdot 4$ \\
\hline Sanyo $†$ (Pennisetum typhoideum) & $12 \cdot 2$ & 2.5 & $4 \cdot 4$ & $13 \cdot 2$ \\
\hline Findo + (Digitaria exilis) & $7 \cdot 6$ & - & - & - \\
\hline Maize (Zea mays) & $3 \cdot 1$ & $1 \cdot 2$ & 3.7 & 3.7 \\
\hline Cassava (Mannihot esculenta) & $2 \cdot 1$ & - & - & 0.1 \\
\hline Other & $13 \cdot 8$ & 0.8 & $0 \cdot 4$ & $2 \cdot 9$ \\
\hline
\end{tabular}

* Data for 1981 and 1987 are for Keneba and the neighbouring villages of Kanton Kunda and Manduar; those for 1988 and 1989 are for Keneba only.

$\uparrow$ Type of millet.

Table 3. Mean weights $(\mathrm{kg})$ of raw staple per meal eaten by West African villagers*

\begin{tabular}{|c|c|c|c|c|c|c|}
\hline \multirow[b]{2}{*}{ Staple } & \multicolumn{2}{|c|}{1987} & \multicolumn{2}{|c|}{1988} & \multicolumn{2}{|c|}{1989} \\
\hline & $n \dagger$ & Mean wt & $n \dagger$ & Mean wt & $n \dagger$ & Mean wt \\
\hline Rice (Oryza sativa) & 446 & $1 \cdot 28$ & 518 & 1.38 & 656 & $1 \cdot 35$ \\
\hline Sorghum (Sorghum gambicum/margaritiferum) & 22 & 1.04 & 5 & 1.60 & 12 & 1.35 \\
\hline Sanyo millet (Pennisetum typhoideum) & 12 & 1.09 & 25 & $1 \cdot 50$ & 110 & 1.87 \\
\hline Suno millet (Pennisetum gambiense) & 2 & 1.33 & 2 & 2.53 & - & - \\
\hline Maize (Zea mays) & 6 & 0.39 & 21 & 1.53 & 50 & 1.94 \\
\hline Cassava (Manihot esculenta) & - & - & - & - & 1 & 0.93 \\
\hline Rice/cassava & 1 & 1.08 & - & - & - & - \\
\hline Rice/maize & - & - & - & - & 5 & 1.47 \\
\hline Sorghum/maize & 1 & $1 \cdot 17$ & 1 & 4.01 & - & - \\
\hline
\end{tabular}

* Average values are given here; the family size ranged from two adults plus two children to five adults plus eight children (child $\leqslant 16$ years).

$\dagger$ Number of meals per year based on each staple.

As well as the ingredients in sauces, some items are added as the staple is cooked. These too were weighed and recorded. A summary of these data is given in Table 4.

\section{Sauces}

There are five types of sauce: (1) those made with groundnuts, tia durango being the commonest type of groundnut sauce; (2) sauces made with leaves; (3) bukolo (flour sauce) consists of little other than flour, salt, chilli and water, and is usually made only in the dry season when supplies of other ingredients have run out and fresh leaves are not available; (4) suss tulo (oil stew) is cooked more rarely because oil is expensive; (5) dajiwo is not a proper sauce but is the name used for water that something, commonly fish or pumpkin, has been cooked in (jio is Mandinka for water). Dajiwo is often added to futo dishes. Futo is steamed grain, usually sorghum, with a water content of about $40 \%$ and either water or sauce must be added to make it palatable. The percentage frequency of sauces recorded over 3 years is given in Table 5, and the frequency of observation and average weights of ingredients used in sauces over the 3 years 1987 to 1989 are given in Table 6. Table 7 shows the percentage frequencies of fish eaten in the 3 years 1987 to 1989 . 
Table 4. Mean weights $\left(\mathrm{Wt}_{a v} ; \mathrm{g}\right)$ of additions to staple foods used by West African villagers*广

\begin{tabular}{|c|c|c|c|c|c|c|}
\hline & \multicolumn{2}{|c|}{1987} & \multicolumn{2}{|c|}{1988} & \multicolumn{2}{|c|}{1989} \\
\hline & $W t_{\mathrm{av}}$ & $n \ddagger$ & $W t_{\mathrm{av}}$ & $n \ddagger$ & $W t_{\mathrm{av}}$ & $n \ddagger$ \\
\hline Additions to sorghum & & (22) & & (5) & & (12) \\
\hline Dry baobab leaves & 65 & 13 & 71 & 4 & 62 & 5 \\
\hline Additions to maize & & (6) & & (21) & & $(50)$ \\
\hline Baobab flesh & 56 & 2 & - & - & 739 & 2 \\
\hline Dry baobab leaves & 40 & 1 & 68 & 11 & 75 & 29 \\
\hline Raw groundnuts & - & - & - & - & 260 & 1 \\
\hline Roast groundnuts & - & - & - & - & 190 & 1 \\
\hline Additions to rice & & (446) & & (518) & & $(656)$ \\
\hline Bitter tomato & 120 & 1 & 198 & 2 & - & - \\
\hline Chilli pepper, dry & 9 & 27 & 8 & 21 & 8 & 18 \\
\hline Chilli pepper, fresh & 11 & 7 & 15 & 2 & 20 & 17 \\
\hline Onion & 46 & 5 & 40 & 6 & 59 & 7 \\
\hline Onion leaves & 19 & 2 & 10 & 3 & - & - \\
\hline Raw groundnuts & 241 & 48 & 253 & 58 & 263 & 54 \\
\hline Roast groundnuts & 217 & 10 & 195 & 1 & 240 & 1 \\
\hline Spring onion & 18 & 6 & 26 & 1 & 44 & 2 \\
\hline Sweet pepper & 29 & 1 & - & - & - & - \\
\hline Tomato & 120 & 1 & 一 & - & - & - \\
\hline Locust beans & - & - & 36 & 1 & - & - \\
\hline Okra & - & - & - & - & 100 & 1 \\
\hline Additions to sanyo millet & & (12) & & (25) & & $(110)$ \\
\hline Baobab leaves, dry & 43 & 2 & 64 & 15 & 69 & 66 \\
\hline Baobab leaves, fresh & 109 & 1 & - & - & - & - \\
\hline Bene leaves (Sesamum indicum) & 32 & 1 & - & - & - & - \\
\hline Chilli pepper, dry & - & - & - & - & 7 & 2 \\
\hline Onion leaves & - & - & 一 & - & 41 & 1 \\
\hline Raw groundnuts & 160 & 1 & - & - & 294 & 2 \\
\hline
\end{tabular}

* Average values are given here; the family size ranged from two adults plus two children to five adults plus eight children (child $\leqslant 16$ years).

$\uparrow$ For details of foods, see Table 1 .

$\$$ Number of meals from which $W t_{a v}$ was calculated. The values in parentheses are the total numbers of such meals in the database.

Table 5. Percentage frequency of consumption of various sauces by West African villagers

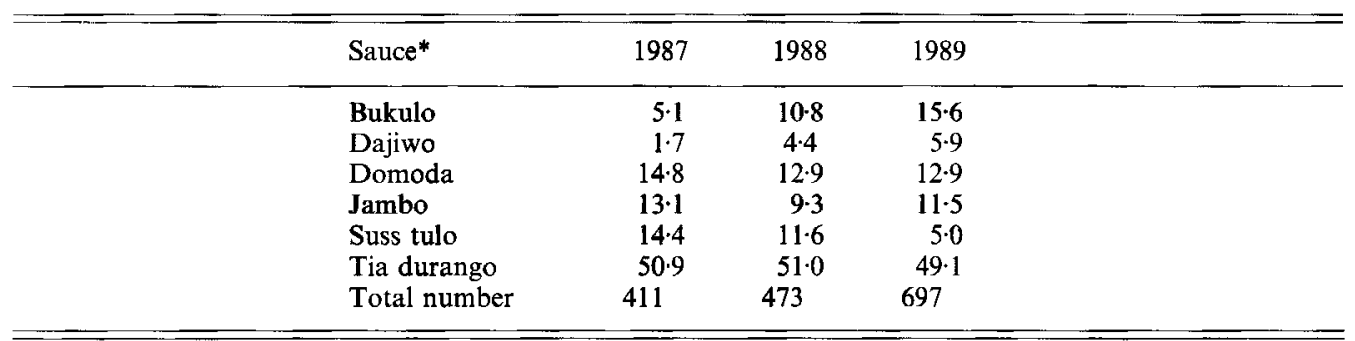

* Bukulo, flour sauce; dajiwo, thin sauce; domoda, sour-leaf sauce; jambo, leaf sauce; suss tulo, oil sauce; tia durango, groundnut sauce. For further details, see p. 557. 
Table 6. Ingredients occurring in sauces consumed by West African villagers between 1987 and 1989*

\begin{tabular}{|c|c|c|c|c|c|}
\hline Ingredient & $W t_{\mathrm{av}}(\mathrm{g}) \dagger$ & $n \ddagger$ & Ingredient & $W t_{\mathrm{av}}(\mathrm{g}) \dagger$ & $n \ddagger$ \\
\hline \multicolumn{3}{|c|}{ 1. Groundnut sauce (tia durango) } & Sweet pepper & 18 & 2 \\
\hline Aubergine & 279 & 12 & Tomato & 185 & 7 \\
\hline \multirow{2}{*}{$\begin{array}{l}\text { Baobab leaves, fresh } \\
\text { dry }\end{array}$} & 5 & 2 & Tomato paste & 38 & 17 \\
\hline & 9 & 85 & Wheat flour & 64 & 1 \\
\hline Baobab milk & 1310 & 1 & 3. Leaf sauces (jambo) & & \\
\hline Bitter tomato & 198 & 39 & Aubergine & 160 & 2 \\
\hline Bosingo (shellfish) & 225 & 4 & Bitter tomato & 189 & 7 \\
\hline Cabbage & 287 & 6 & Cabbage & 531 & 6 \\
\hline Cassava & 239 & 1 & Cassava leaves & 325 & 4 \\
\hline Challo§ & 251 & 15 & Chilli pepper, dry & 9 & 69 \\
\hline \multirow{2}{*}{$\begin{array}{l}\text { Chilli pepper, dry } \\
\text { fresh }\end{array}$} & 8 & 336 & fresh & 15 & 25 \\
\hline & 14 & 98 & Fish, dry & 52 & 11 \\
\hline \multirow{2}{*}{$\begin{array}{l}\text { Fish, dry } \\
\text { smoked }\end{array}$} & 40 & 71 & smoked & 49 & 3 \\
\hline & 92 & 13 & Challo§ & 206 & 8 \\
\hline unspecified & 268 & 3 & Furundingo§ & 29 & 1 \\
\hline \multirow{2}{*}{$\begin{array}{l}\text { Furundingo } \\
\text { Tambajango }\end{array}$} & 355 & 3 & Groundnuts, raw & 323 & 111 \\
\hline & 17 & 1 & roast & 320 & 8 \\
\hline \multirow{2}{*}{$\begin{array}{r}\text { Groundnuts, raw } \\
\text { roast }\end{array}$} & 256 & 54 & Jambanduro & 698 & 30 \\
\hline & 242 & 552 & Leaves (any) & 746 & 10 \\
\hline Kucha leaves & 76 & 6 & Locust bean & 16 & 1 \\
\hline Lime, fresh & 27 & 1 & Maggi cube & 9 & 30 \\
\hline \multirow{2}{*}{$\begin{array}{l}\text { Locust bean } \\
\text { Maggi cube }\end{array}$} & 48 & 7 & Maize flour & 203 & 1 \\
\hline & 9 & 268 & Morongo leaves & 649 & 59 \\
\hline $\begin{array}{l}\text { Maggi cube } \\
\text { Maize flour }\end{array}$ & 72 & 18 & Nebedayo leaves & 422 & 12 \\
\hline Maize/rice flour & 27 & 1 & Okra & 324 & 3 \\
\hline \multirow{2}{*}{$\begin{array}{l}\text { Maize/suno flour } \\
\text { Meat }\end{array}$} & 17 & 1 & Okra leaves & 38 & 1 \\
\hline & 375 & 8 & Onion, large & 63 & 27 \\
\hline Okra & 35 & 13 & leaves & 40 & 12 \\
\hline Onion, large & 50 & 8 & spring & 43 & 31 \\
\hline \multirow{2}{*}{$\begin{array}{l}\text { leaves } \\
\text { spring }\end{array}$} & 15 & 8 & Palm oil & 7 & 193 \\
\hline & 36 & 34 & Pumpkin & 1292 & 2 \\
\hline \multirow{2}{*}{$\begin{array}{l}\text { Palm oil } \\
\text { Pumpkin }\end{array}$} & 20 & 142 & Rice flour & 39 & 1 \\
\hline & 375 & 2 & Salt & 25 & 122 \\
\hline Rice flour & 57 & 209 & Sorghum flour & 30 & 1 \\
\hline Rice/sorghum flour & 33 & 1 & Sora leaves & 486 & 2 \\
\hline Salt & 20 & 527 & Sweet pepper & 286 & 7 \\
\hline Sanyo flour & 68 & 104 & Tomato paste & 22 & 1 \\
\hline Sorghum flour & 50 & 43 & Wheat flour & 590 & 1 \\
\hline Sorrel fruit (Hibiscus sp.) & 4 & 3 & 4. Oil stews (suss tulo) & & \\
\hline Sugar & 138 & 1 & Aubergine & 239 & 14 \\
\hline Suno flour & 43 & 8 & Bitter tomato & 148 & 11 \\
\hline Sweet pepper & 31 & 29 & Black pepper & 3 & 14 \\
\hline Tomato paste & 38 & 373 & Cabbage & 362 & 7 \\
\hline Tomato, fresh & 261 & 171 & Cassava & 225 & 4 \\
\hline 2. Sour-leaf sauces (domoda) & & & Chilli pepper, dry & 9 & 77 \\
\hline Aubergine & 397 & 2 & fresh & 24 & 28 \\
\hline Baobab leaves, fresh & 16 & 1 & Fish, dry & 48 & 4 \\
\hline dry & 10 & 21 & unspecified & 793 & 2 \\
\hline Bitter tomato & 317 & 8 & Challo§ & 291 & 3 \\
\hline Chilli pepper, dry & 10 & 68 & Furundingo§ & 380 & 1 \\
\hline fresh & 21 & 23 & Groundnut oil & 56 & 357 \\
\hline Fish, dry & 36 & 33 & Groundnuts, raw & 342 & 1 \\
\hline smoked & 50 & 2 & Leaves (any) & 449 & 1 \\
\hline Challo§ & 32 & 3 & Locust bean & 30 & 3 \\
\hline Furundingo§ & 481 & 2 & Maggi cube & 10 & 54 \\
\hline Groundnuts, roast & 196 & 1 & Morongo leaves & 478 & 1 \\
\hline
\end{tabular}


Table 6. (cont.)

\begin{tabular}{lrrlrrr}
\hline \hline Ingredient & $W t_{\text {av }}(\mathrm{g}) \dagger$ & $n \ddagger$ & Ingredient & & $W t_{\text {av }}(\mathbf{g}) \dagger$ & $n \ddagger$ \\
\hline Kucha leaves & 248 & 122 & Okra & 375 & 6 \\
Locust bean & 34 & 12 & Onion, large & & 95 & 71 \\
Maggi cube & 9 & 57 & leaves & 4 & 3 \\
Maize flour & 51 & 10 & spring & 78 & 37 \\
Maize/rice flour & 12 & 1 & Palm oil & 24 & 327 \\
Okra & 114 & 22 & Pumpkin & 473 & 6 \\
Onion, large & 48 & 3 & Salt & 21 & 104 \\
$\quad$ spring & 21 & 2 & Sweet pepper & 154 & 13 \\
Palm oil & 6 & 122 & Tomato & 250 & 27 \\
Rice flour & 49 & 18 & Tomato paste & 53 & 105 \\
Salt & 16 & 102 & Vegetable oil & & 26 & 300 \\
Sanyo flour & 26 & 4 & & & \\
Sorghum flour & 34 & 8 & & & & \\
Suno flour & 25 & 1 & & & \\
\hline \hline
\end{tabular}

* For details of foods, see Table 1.

$\dagger$ Average weight of the ingredient used in the sauce (g).

$\$$ Number of meals from which $W t_{\mathrm{av}}$ was calculated.

$\S$ Type of fish.

Table 7. Percentage frequency of fish in the diet of West African villagers

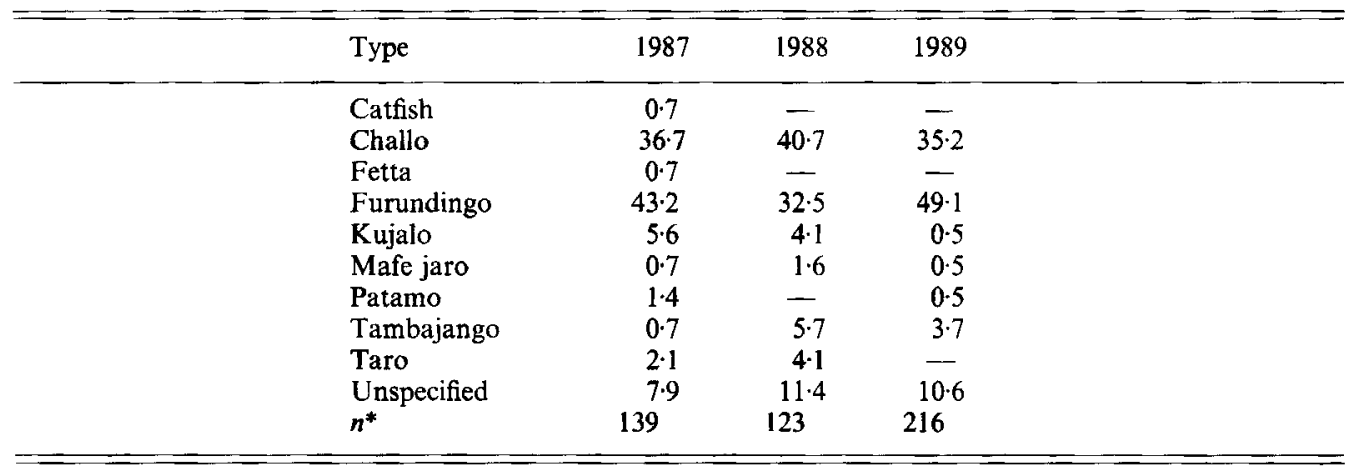

* Number of meals that included the fish.

Measurement of total energy expenditure by the doubly-labelled water method

Validity of the data. The quality of the data obtained from the doubly-labelled water studies of total energy expenditure reported here may be judged following the recommendations of the International Dietary Energy Consultancy Group (IDECG) of the International Atomic Energy Agency (IDECG, 1990).

Ratio of the isotope distribution spaces. Total body water space may be estimated from the $y$ intercept of a least-squares fit for the regression of $\ln$ isotope enrichment $v$. time. The space determined from the data for the ${ }^{2} \mathrm{H}$ isotope $\left(N_{\mathrm{D}}\right)$ is always larger than that obtained from the data for the ${ }^{18} \mathrm{O}$ isotope $\left(N_{\mathrm{o}}\right)$. The ratio of the two values $N_{\mathrm{D}} / N_{\mathrm{O}}$ is characteristically $1.03( \pm 0.02)$, and the IDECG (1990) recommend that any data for which $N_{\mathrm{D}} / N_{\mathrm{o}}$ is outside the range 1.015 to 1.06 should be treated with scepticism.

Coward (1988) published values for the ratio of the isotope distribution spaces in a 
Table 8. Variation in background levels of enrichment of ${ }^{18} \mathrm{O}$ measured in the urine of West African villagers

\begin{tabular}{|c|c|c|c|c|c|c|}
\hline \multirow[b]{2}{*}{ Subject... } & \multicolumn{2}{|c|}{ January } & \multicolumn{2}{|c|}{ July } & \multicolumn{2}{|c|}{ October } \\
\hline & A & B & $\mathrm{C}$ & B & $\mathbf{E}$ & F \\
\hline $\begin{array}{l}\text { Mean } \\
\text { SD }\end{array}$ & $\begin{array}{r}-0.515 \\
-0.560 \\
-0.768 \\
-0.704 \\
-0.637 \\
+0.364 \\
-0.518 \\
-0.487 \\
-0.307 \\
-0.476 \\
- \\
-0.461 \\
0.317\end{array}$ & $\begin{array}{r}-2.542 \\
-2.724 \\
-2.612 \\
-2.537 \\
-2.640 \\
-2.918 \\
-2.683 \\
-2.488 \\
-2.685 \\
-2.896 \\
-2.673 \\
0.144\end{array}$ & $\begin{array}{r}-2.470 \\
-2.494 \\
-2.440 \\
-3.040 \\
-3.024 \\
-2.461 \\
-2.058 \\
-2.274 \\
-2.754 \\
-1.397 \\
-1.997 \\
-2.397 \\
0.474\end{array}$ & $\begin{array}{r}-2.967 \\
-2.123 \\
-2.613 \\
-2.807 \\
-2.683 \\
-2.420 \\
-1.453 \\
-2.224 \\
-2.266 \\
-2.482 \\
-2.404 \\
0.427\end{array}$ & $\begin{array}{r}-2.504 \\
-2.309 \\
-2.784 \\
1.495 \\
-2.499 \\
-2.050 \\
-2.178 \\
-3.086 \\
-2.512 \\
-3.382 \\
-3.344 \\
-2.558 \\
0.568\end{array}$ & $\begin{array}{r}-2.858 \\
-\mathbf{3} \cdot 183 \\
-\mathbf{3} \cdot 541 \\
-2.672 \\
-2.741 \\
-3.632 \\
-3.461 \\
-3.238 \\
-\mathbf{3} \cdot 639 \\
-\mathbf{3} \cdot 785 \\
-2.934 \\
-3.244 \\
0.395\end{array}$ \\
\hline
\end{tabular}

variety of subjects with an average value for the ${ }^{2} \mathrm{H}$ distribution space ${ }^{18} \mathrm{O}$ distribution space ratio of about $1 \cdot 035$. Values for the standard deviation ranged from 0.009 to 0.013 for seven groups of subjects but were 0.020 for Cambridge infants of less than 6 months and 0.024 for Gambian men, two groups where water turnover rates are high. The data from The Gambia are taken from a study of men who were road-building in Keneba (Diaz et al. 1990). This large value of the standard deviation has been suggested as possibly the result of large changes in day-to-day background levels of enrichment of the two isotopes. If these variations existed they would influence the results obtained from the mathematical model used by Coward (1988), since that model makes a correction for background levels of enrichment for the two isotopes from measurement of the pre-dose sample but then assumes that they are constant throughout the measurement period. The ${ }^{18} \mathrm{O}$ enrichment values were measured for samples collected from the controls in January, July and October, and the assumption was made that any variation in levels would be covariant for the two isotopes. Values obtained on consecutive days for two subjects at each measurement period are given as examples in Table 8, and they suggest that day-to-day variation in background enrichment levels is small.

Table 9 shows the values obtained for the ratio of isotope distribution spaces in these studies. Not all the values meet the IDECG criterion of $>1.015$ and $<1.06$. In particular, the studies done in July yielded $N_{\mathrm{D}} / N_{\mathrm{o}}$ values ranging from 1.06 to $1 \cdot 11$ for five of the seven subjects. There is no obvious reason why this should be so. Recalculation of the data for all seven subjects in July after removal of paired ${ }^{18} \mathrm{O}$ and ${ }^{2} \mathrm{H}$ values that did not differ from the fitted lines in a covariant manner resulted in an improvement for three subjects, no difference for one, and even more deviant values for the other three (results not shown).

If the twenty-one values for January, April and October are considered together then one value would be rejected because it is considerably greater than $1.03+0.02$. The mean value for the remaining twenty studies is 1.0325 (SD 0.017). However, when all twenty-eight studies are included the mean is 1.049 (SD 0.036). Except for the one 'rejected' value in October, all the 'noise' comes from the values obtained in July, for which the mean is 1.09 (SD 0.038 ); the values range from 1.03 to $1 \cdot 14$. The data have been scrutinized extremely carefully and there is no evidence for a methodological error. 
Table 9. Ratios of isotope distribution spaces in studies of subjects in a West African village*

\begin{tabular}{|c|c|c|c|c|}
\hline Subject & January & April & July & October \\
\hline 1 & 1.02 & 1.05 & 1.09 & $1 \cdot 13$ \\
\hline 2 & 1.05 & 1.04 & 1.05 & 1.01 \\
\hline 3 & - & $1 \cdot 04$ & 1.03 & 1.00 \\
\hline 4 & 1.05 & 1.03 & $1 \cdot 11$ & 1.02 \\
\hline 5 & 1.02 & 1.03 & $1 \cdot 11$ & 1.03 \\
\hline 6 & 1.02 & 1.06 & $1 \cdot 14$ & 1.03 \\
\hline 7 & 1.03 & - & - & - \\
\hline \multirow[t]{2}{*}{8} & 1.06 & 1.05 & 1.07 & $1 \cdot 01$ \\
\hline & & Mean & SD & $n$ \\
\hline \multirow{2}{*}{\multicolumn{2}{|c|}{$\begin{array}{c}\mathrm{Jan}+\mathrm{Apr}+(\text { Oct }- \text { Subject } 1) \\
\text { All data }\end{array}$}} & 1.03 & 0.017 & 20 \\
\hline & & 1.05 & 0.036 & 28 \\
\hline \multicolumn{2}{|c|}{ July alone } & 1.09 & 0.038 & 7 \\
\hline
\end{tabular}

${ }^{*}$ For details, see pp. 560-561.

The implication is that there may be an explanation in physiological terms. Values for $N_{\mathrm{D}} / N_{\mathrm{o}}$ of the order of 1.05 could be expected if there is some physiological mechanism associated with physical exercise whereby deuterium is depleted from the body more rapidly than the ${ }^{18} \mathrm{O}$ isotope. It has been suggested that increased muscular activity leads to higher protein turnover with a concomitant increase in exposure of $\mathbf{H}$ atoms for exchange. This is more plausible than the postulate that there is an increase in the pool of exchangeable $\mathrm{H}$ atoms in the body at this particular time of year of sufficient magnitude to account for the observed values. However, if the phenomenon of increased protein turnover leads to such values it is curious that they were not seen by Diaz et al. (1990) in their studies of men who were engaged in road-building.

Residuals of the disappearance curves. The residuals, the differences between observed values and the line of best fit for the regression of $\ln$ isotope enrichment values $v$. time, should be small and covariant; i.e. the sign of the residual should be the same for both isotopes at each time point. The majority of the data, including the July data that lead to peculiar $N_{\mathrm{b}} / N_{\mathrm{o}}$ values, fulfil these criteria. A few residuals were unacceptably large and were omitted from the calculations but there was little evidence for non-covariance in any of the data sets. Figs 1 and 2 show the fits and the residuals for a subject in April, using all the samples for the calculations (Fig. 1), and using just three early and three late time points (Fig. 2) as recommended by Coward (1988). The same analyses and calculations were done for a second subject (results not shown). Essentially the same plots result whether eleven or six data points are used. These data are typical of all the data obtained, except for the unexplained large values for the ratio of water spaces found in July. Once these data were available it was considered reasonable to measure only the first three and last three samples for all other subjects.

Ratios and residuals. A good fit with small residuals for the regression of $\ln N_{\mathrm{D}} / N_{\mathrm{O}} v$. time indicates relatively constant rates of $\mathrm{CO}_{2}$ production and adequate analytical technique. Figs $1(c)$ and 2(c) illustrate the fit for the ln ratio values $v$. time and Figs $1(d)$ and $2(d)$ show the residuals for these plots. The fits are good and the residuals are small. The $N_{\mathrm{D}} / N_{\mathrm{o}}$ value is indicated directly as the $y$-intercept of the enrichment ratio plot $v$. time; e.g. an intercept of +0.03 on the logarithmic scale is equivalent to $N_{\mathrm{D}} / N_{\mathrm{O}}=1.03$.

Products and residuals. Examination of the plots for $\ln$ enrichment $v$. time provides 

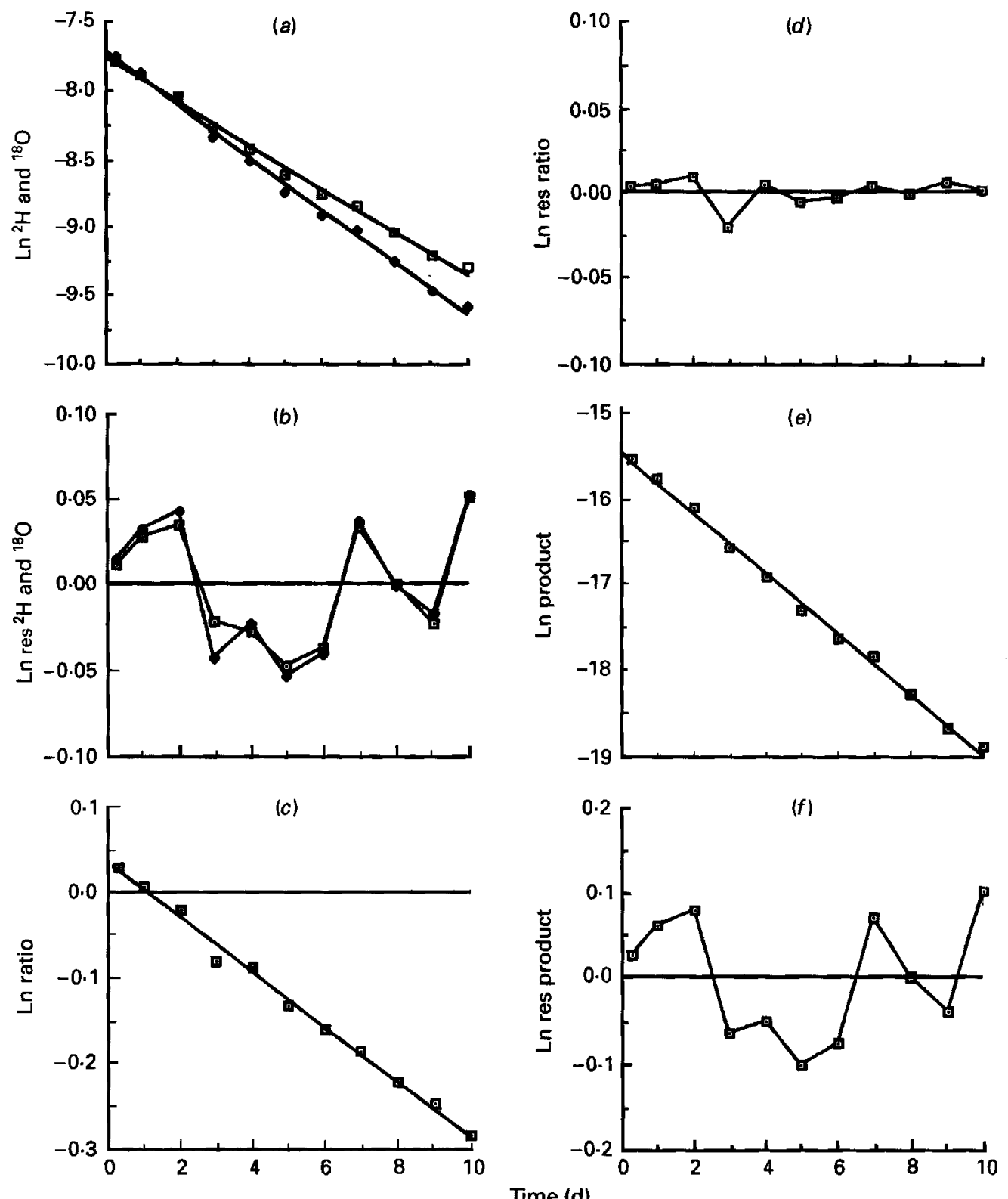

Fig. 1. (a) Subject 1, all data. A plot of $\ln ^{2} H$ enrichment $(\cdot)$ and of $\ln ^{18} \mathrm{O}$ enrichment $(\bullet)$ against time, and the least-squares linear fit for each. (b) Subject 1, all data. The residuals (res) from the fitted line for $\ln { }^{2} \mathrm{H}$ and $\ln { }^{18} \mathrm{O}$ enrichment, illustrating the covariance of the deviations. (c) Subject 1, all data. A plot of the ratio of the values for $\ln { }^{2} \mathrm{H}$ and $\ln { }^{18} \mathrm{O}$ enrichment, and the least-squares linear fit. (d) Subject 1, all data. A plot of the residuals (res) for the deviations from the fitted line for the ratio of the values for $\ln ^{2} \mathrm{H}$ and $\ln ^{18} \mathrm{O}$ enrichment. (e) Subject 1 , all data. A plot of the product of the values for $\ln ^{2} \mathrm{H}$ and $\ln ^{18} \mathrm{O}$ enrichment, and the least-squares linear fit. ( $f$ ) Subject 1, all data. A plot of the residuals for the deviation from the fitted line for the product of the values for $\ln ^{2} \mathrm{H}$ and $\ln { }^{18} \mathrm{O}$ enrichment. 

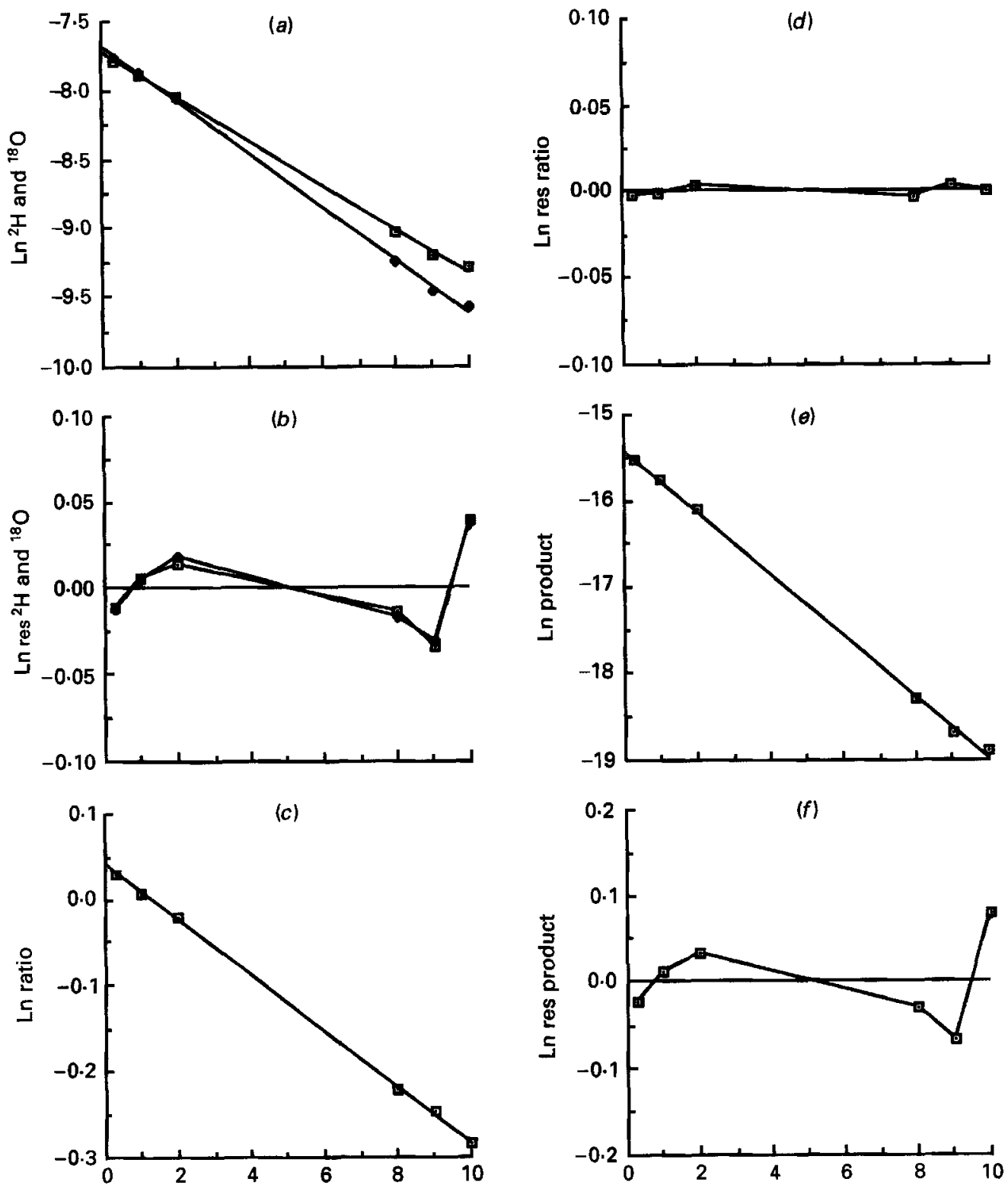

Time (d)

Fig. 2. (a) Subject 1, restricted data. A plot of the values for $\ln ^{2} \mathrm{H}$ enrichment ( $(\mathrm{g})$ and $\ln { }^{18} \mathrm{O}$ enrichment ( $)$ against time, and the least-squares linear fit for each. (b) Subject 1, restricted data. A plot of the residuals (res) from the fitted lines for $\ln ^{2} \mathrm{H}$ and $\ln ^{18} \mathrm{O}$ enrichment, illustrating the covariance of the deviations. (c) Subject 1 , restricted data. A plot of the ratio of the values for $\ln ^{2} \mathrm{H}$ and $\ln ^{18} \mathrm{O}$ enrichment, and the least-squares linear fit. (d) Subject 1, restricted data. A plot of the residuals (res) for the deviations from the fitted line for the ratio of the values for $\ln ^{2} \mathrm{H}$ and $\ln ^{18} \mathrm{O}$ enrichment. (e) Subject 1, restricted data. A plot of the product of the $\ln ^{2} \mathrm{H}$ and $\ln ^{18} \mathrm{O}$ enrichment values, and the least-squares linear fit. $(f)$ Subject 1 , restricted data. A plot of the residuals for the deviation from the fitted line for the product of the values for $\ln ^{2} \mathrm{H}$ and $\ln ^{18} \mathrm{O}$ enrichment. 
Table 10. Average energy expenditure and intake for seven men in a West African village during 1989

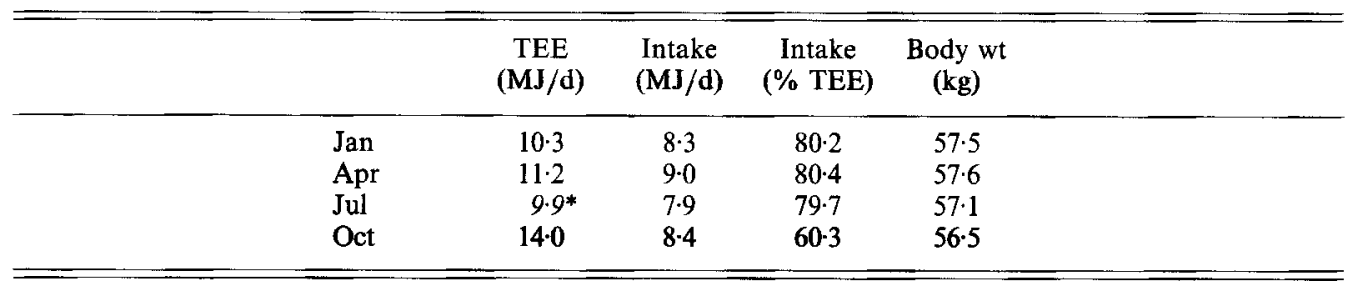

TEE, total energy expenditure.

* See p. 566.

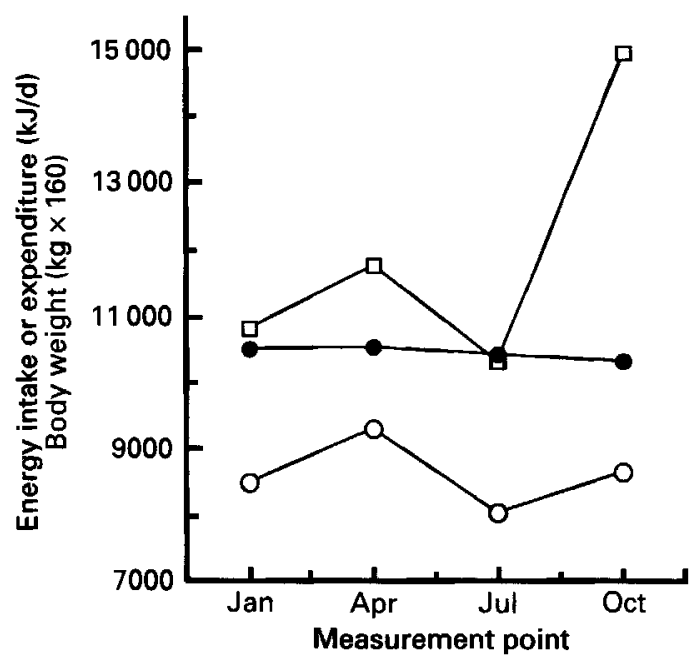

Fig. 3. The relation between the average values for total energy expenditure $(\square)$, energy intake $(O)$ and body weight ( ) for men in a West African village in January, April, July and October 1989. (The body weights are multiplied by 160 for convenience of plotting on a common $y$-axis.)

information about rates of water turnover. A good fit to the line with small residuals indicates the absence of fluctuations in water turnover. Figs $1(f)$ and $2(f)$ show that the residuals here are quite large. This will not necessarily affect the calculations of total energy expenditure (TEE) since the $\mathrm{CO}_{2}$ production rates are relatively constant, as shown by the ratio plots, but could result in bias in the calculation of body water space if the intercept is very different from that predicted from the early points. In general, the data obtained in these studies are satisfactory as judged by these criteria.

\section{Compatibility of the observed values for energy intake and expenditure}

The measurements of TEE were intended to serve, at least in part, as reference values for the estimates of energy intakes. Here, the average values for TEE, intake and body weight are used to judge the success of the methodology used for estimating energy intakes.

Table 10 shows the average values for TEE measured for seven adult male subjects, the average values estimated for the energy intake of men, both as absolute values and as a 


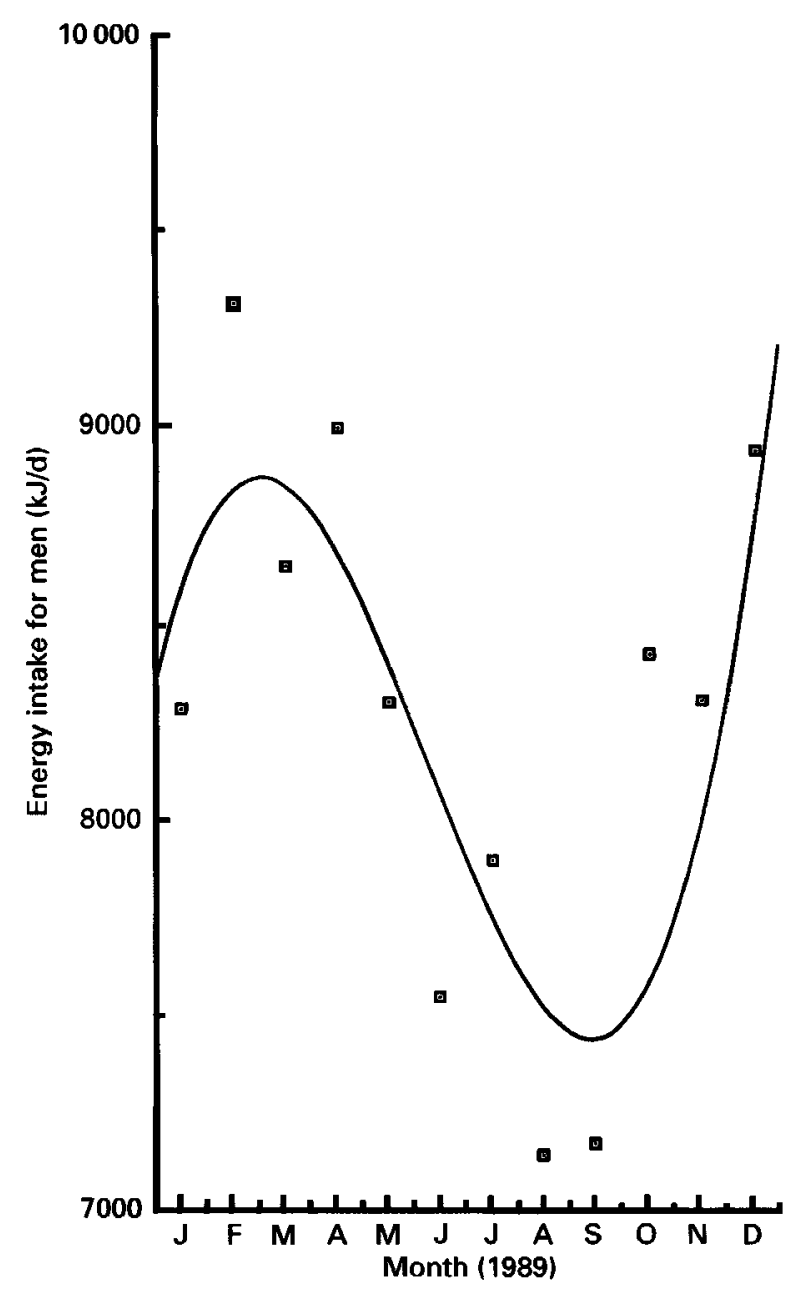

Fig. 4. Seasonal changes in dietary energy intake by men in a West African village, with the best-fit, third-degree polynomial.

percentage of the appropriate TEE value, and the average body weight recorded for all adult males between the ages of 20 and 60 years in January, April, July and October 1989.

The intake values are $80 \%$ of the TEE values in January and April, and there is no change in body weight. The same percentage is recorded for the data obtained in July but the TEE value is shown in italic type as a reminder of the discussion of the validity of this value. Nonetheless, the TEE values for January, April and July are similar. There is a marked increase in TEE in October, the value is $30 \%$ higher than the average value for January and April. The value for energy intake in October is not very different from that for the other time points and, as a result, is only $60 \%$ of TEE. However, the average body weight has decreased by $1 \mathrm{~kg}$ from the values recorded in January and April, suggesting that the increase in TEE has resulted in a decrease in body weight in the absence of an increase in energy intake. The relation is illustrated by Fig. 3.

The data for men in 1989 are illustrated by Fig. 4 . The data are well described by a thirddegree polynomial, emphasizing the seasonal changes. The average values, over all families, in 1987, 1988 and 1989 are given in Table 11. 
Table 11. Calculated energy intakes $(M J / d)$ from cooked food by men $(M)$, women $(W)$, boys $(\leqslant 16$ years; $B)$ and girls $(\leqslant 16$ years; $G)$ in a West African village in the years 1987-1989

\begin{tabular}{|c|c|c|c|c|c|c|c|c|c|c|c|c|c|c|}
\hline & \multicolumn{4}{|c|}{1987} & & \multicolumn{4}{|c|}{1988} & & \multicolumn{4}{|c|}{1989} \\
\hline & $\mathbf{M}$ & $\mathbf{W}$ & B & $\mathbf{G}$ & & $\mathbf{M}$ & $\mathbf{W}$ & B & $\mathbf{G}$ & & $\mathbf{M}$ & $\mathbf{W}$ & B & $\mathbf{G}$ \\
\hline Feb & 6.7 & 5.0 & 3.5 & $2 \cdot 9$ & Mar & 8.0 & 6.0 & $3 \cdot 3$ & 2.9 & Jan & $8 \cdot 3$ & 6.8 & $4 \cdot 4$ & $3 \cdot 5$ \\
\hline Mar & $7 \cdot 7$ & $7 \cdot 0$ & 4.8 & 4.8 & Apr & $7 \cdot 4$ & $5 \cdot 5$ & $2 \cdot 8$ & $2 \cdot 8$ & Feb & $9 \cdot 3$ & $6 \cdot 1$ & $4 \cdot 1$ & $3 \cdot 5$ \\
\hline Apr & 6.4 & $6 \cdot 4$ & 3.4 & $3 \cdot 2$ & May & $9 \cdot 1$ & 5.9 & $3-4$ & $3 \cdot 0$ & Mar & $8 \cdot 6$ & $6 \cdot 5$ & $3 \cdot 8$ & $3 \cdot 3$ \\
\hline May* & 5.0 & $3 \cdot 5$ & $3 \cdot 7$ & $3 \cdot 1$ & Jun & 7.6 & 6.0 & $3 \cdot 0$ & $2 \cdot 6$ & Apr & $9 \cdot 0$ & $7 \cdot 8$ & 5.0 & $3 \cdot 3$ \\
\hline Jun & $7 \cdot 7$ & $6 \cdot 4$ & $4 \cdot 3$ & 3.0 & Jul & $8 \cdot 7$ & $6 \cdot 1$ & 3.9 & $3 \cdot 4$ & May & $8 \cdot 3$ & 6.0 & $4 \cdot 0$ & 3.0 \\
\hline Jul & $8 \cdot 1$ & 6.6 & $4 \cdot 0$ & $3 \cdot 3$ & Aug & $7 \cdot 9$ & $6 \cdot 2$ & $3 \cdot 1$ & $2 \cdot 5$ & Jul & $7 \cdot 9$ & $5 \cdot 8$ & $3 \cdot 2$ & $2 \cdot 9$ \\
\hline Aug & 8.6 & 6.6 & $4 \cdot 1$ & $3 \cdot 3$ & Sep & $8 \cdot 8$ & 6.6 & $3-9$ & $3 \cdot 1$ & Aug & $7 \cdot 1$ & $6 \cdot 5$ & 3.4 & $2 \cdot 9$ \\
\hline Sep & 7.7 & $6 \cdot 5$ & 3.7 & $3 \cdot 2$ & Oct & 8.9 & $6 \cdot 2$ & 30 & $2 \cdot 4$ & Sep & $7 \cdot 2$ & $6 \cdot 0$ & $4 \cdot 2$ & $3 \cdot 2$ \\
\hline Oct & 7.9 & 6.9 & 3.6 & $3 \cdot 1$ & Nov & $8 \cdot 2$ & 5.4 & $4 \cdot 1$ & $3 \cdot 0$ & Oct & 8.4 & $6 \cdot 5$ & $4 \cdot 1$ & 3.0 \\
\hline Nov & 6.8 & $5 \cdot 6$ & 3.8 & 3.4 & Dec & $8 \cdot 7$ & 6.5 & 3.8 & 3.0 & Dec & 8.9 & $6 \cdot 1$ & $3 \cdot 3$ & 3.0 \\
\hline
\end{tabular}

* Ramadan; values shown in italics are for the evening meal only. The April and May values for 1988 and 1989 are for only the non-Ramadan days in those months.

\section{DISCUSSION}

Measurement of total energy expenditure with doubly-labelled water

The doubly-labelled water (DLW) method for the measurement of TEE has been developed for use with free-living human subjects on the basis of a model proposed by Lifson \& McClintock (1966). Subjects receive a dose of water that is enriched, relative to background, for the two naturally occurring stable isotopes ${ }^{2} \mathrm{H}$ and ${ }^{18} \mathrm{O}$. The subsequent collection and analysis of body fluid, usually urine, from the subject over a period of time (10-14 $\mathrm{d}$ for adult humans) allows the rates of loss of ${ }^{2} \mathrm{H}$ and ${ }^{18} \mathrm{O}$ from the body to be determined. In the model it is assumed: (1) that the isotopes ${ }^{2} \mathrm{H}$ and ${ }^{18} \mathrm{O}$ label body water, and are lost from body water, as if it is a single compartment; and (2) that ${ }^{2} \mathrm{H}$ is lost from the body only as water but that ${ }^{18} \mathrm{O}$ is lost from the body both as water and as $\mathrm{CO}_{2}$. As a result, the rate of disappearance of ${ }^{18} \mathrm{O}$ from the body is greater than that for ${ }^{2} \mathrm{H}$, and the difference between the rates of loss is a measure of $\mathrm{CO}_{2}$ production, which is related to energy expenditure. Underlying the mathematics of the model are three further assumptions: (1) total body water, and output rates of water and of $\mathrm{CO}_{2}$ are constant; (2) water and $\mathrm{CO}_{2}$ losses occur with the same enrichment as that coexisting in body water; and (3) background isotope intake rates are constant. If all these assumptions were demonstrated to be true then it would be a simple matter to determine TEE with great accuracy. However, none of the assumptions is true. Coward \& Cole (1991) have presented a detailed examination of the likely magnitude of error in the calculated value of TEE contributed by the deviations from these assumptions encountered in vivo and concluded '... likely errors can be fairly well assessed for most conceivable subjects and environmental circumstances. Provided this is done, estimates of energy expenditure using double labelled water should prove reliable.'

To provide a reference for the measurements of energy intakes in the present study, seven adult males were recruited for the measurement of TEE by the doubly-labelled water method. Measurements were made on four occasions in 1989 at approximately 3-monthly intervals. A further seven adult males were recruited on each occasion to provide daily samples of urine during the measurement periods as controls for fluctuations in background enrichments.

The methodology developed and applied in these studies yields values for dietary energy 
intake that are of the order of $80 \%$ of values obtained for TEE. This is a highly satisfactory result, since no attempt was made to measure any source of energy intake other than that supplied by two cooked meals per day. This value should be compared with the results reported by Singh et al. (1988), who applied the methodology previously used in this community for measuring total food intake and the doubly-labelled water technique for the measurement of TEE. They obtained values for total dietary energy intake that were of the order of only $50 \%$ of their values for TEE.

The problem remains of the validation of the intake data. In a study of methodology, Kretsch \& Fong (1990) stated 'To validate dietary intake methodology, it is necessary to obtain an independent measure of actual intake. Because this is virtually impossible under field conditions,...' and their solution was to compare methods with subjects living in a calorimeter for 16 consecutive days. In the studies described here the doubly-labelled water technique was used to provide values for TEE over 11 consecutive days, which have been used as an indirect reference for energy intake. The suggestion is made here that the energy intake values recorded are of the order of $80 \%$ of true intake. When energy expenditure rose during the farming season the estimated intake was of the order of $60 \%$ of expenditure. However, body weight loss was recorded at that time, so the value of $80 \%$ of true intake may well be applicable throughout the year. No attempt was made to measure food intake at any time other than at the midday and the evening meals. There are several possible sources of error in these estimations of food intake. For example: (1) the distribution algorithm may be inappropriate. (2) Special meals and/or amounts of food may have been prepared because the cook was under observation. (3) A great deal of food may have been consumed at breakfast or away from the home. (4) Incorrect values for the energy content of foods may have been used in the calculations of intake.

(1) Distribution algorithm: the appropriateness of the algorithm can be judged only by the results obtained; there is no gold standard. Nonetheless, the values obtained by its application are entirely reasonable and in keeping with the subjects' body weights. (2) Given the limited resources and availability of food in this community, it is extremely unlikely that atypical meals were cooked. The food intake of a group of people was studied, not that of an individual, so the preparation and consumption of atypical meals at the two main meal times for the 4 consecutive days of each study period would have required a remarkable degree of co-operation and conspiracy. Further, any significant deviation from normal behaviour would have been noticed by the fieldworkers. (3) Given that the estimated energy intakes are of the order of $80 \%$ of TEE throughout much of the year, the consumption of amounts of food representing significantly more than the 'missing' $20 \%$ of energy intake would have resulted in weight gain. This was not observed. (4) The energy values for foods used for the calculation of energy intake were taken from a variety of sources, and some were derived, as discussed above. It is unlikely that the use of average compositional values would have introduced significant errors into the calculations.

\section{CONCLUSION}

Groups of people eating from a shared bowl of food is not a habit restricted to The Gambia, nor to West Africa. The methodology described here should be readily adaptable to other societies where this particular obstacle to measuring food intake exists. The algorithm used in the present work to estimate the distribution of food within a mixed sex and age group is likely to be appropriate in most circumstances, unless detailed knowledge of local customs suggests otherwise. A combination of the measurement of total energy expenditure by the doubly-labelled water technique and anthropometric data provides reference values to judge the accuracy of values obtained for dietary energy intakes. 
The majority of the fieldwork was done by MRC Gambian fieldworkers as a team ably led by Mr Baba S. N. Jobarteh.

\section{REFERENCES}

Anderson, T. L., Heird, W. C. \& Winters, R. W. (1977). Clinical and physiological consequences of total parenteral nutrition in the paediatric patient. In Current Concepts in Parenteral Nutrition, pp. 111-127 [J. M. Greep, P. B. Soeters, R. I. C. Westorp, C. W. R Phaf and J. E. Fischer, editors]. The Hague: Nijhoff Medical Division.

Bingham, S. A. (1987). The dietary assessment of individuals: methods, accuracy, new techniques and recommendations. Nutrition Abstracts and Reviews Series A 57, 705-742.

Bingham, S. A. (1991). Limitations of the various methods for collecting dietary intake data. Annals of Nutrition and Metabolism 35, 117-127.

Borrelli, R. (1990). Collection of food intake data: a reappraisal of criteria for judging the methods. British Journal of Nutrition 63, 411-417.

Coward, W. A. (1988). The doubly-labelled water $\left({ }^{2} \mathrm{H}_{2}{ }^{18} \mathrm{O}\right)$ method: principles and practice. Proceedings of the Nutrition Society 47, 209-218.

Coward, W. A. \& Cole, T. J. (1991). The doubly labeled water method for the measurement of energy expenditure in humans: risks and benefits. In New Techniques in Nutritional Research, pp. 137-176 [R. G. Whitehead and A. Prentice, editors]. New York: Academic Press.

Diaz, E., Goldberg, G. R., Taylor, M., Savage, J. M., Sellen, D., Coward, W. A. \& Prentice, A. (1990). Effects of dietary supplementation on work performance in Gambian labourers. Proceedings of the Nutrition Society 49, 44A.

Hudson, G. J. (1992). Food intake in a West African village. PhD Thesis, CNAA, London.

Hudson, G. J. \& Day, K. C. (1989). Water content of the rural Gambian diet. Nutrition Reports International 40, 335-339.

International Dietary Energy Consultancy Group (1990). The Doubly-labelled Water Method for Measuring Energy Expenditure. Technical Recommendations for Use in Humans [A. M. Prentice, editor]. Vienna: International Atomic Energy Agency.

Kretsch, M. J. \& Fong, A. K. H. (1990). Validation of a new computerized technique for quantitating individual dietary intakes - the Nutrition Evaluation Scale System (NESSY) vs the weighed food record. American Journal of Clinical Nutrition 51, 477-484.

Lifson, N. \& McClintock, R. (1966). Theory of use of the turnover rates of body water for measuring energy and material balance. Journal of Theoretical Biology 12, 46-74.

Paul, A. A. \& Southgate, D. A. T. (1978). McCance \& Widdowson's Composition of Foods, 4th ed. London: H.M. Stationery Office.

Platt, B. S. (1962). Tables of Representative Values of Foods Commonly Used in Tropical Countries. MRC Special Report Series no. 302. London: H.M. Stationery Office.

Singh, J., Coward, W. A., Prentice, A. M., Ashford, J., Sawyer, M., Diaz, E. \& Whitehead, R. G. (1988). Doublylabelled water measurements of energy expenditure in Gambian women during the agricultural season Proceedings of the Nutrition Society 47, 41A. 